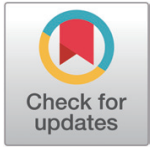

Received: Aug 5, 2021

Revised: Aug 19, 2021

Accepted: Sep 27, 2021

\#These authors contributed equally to this work.

${ }^{*}$ Corresponding author

Minho Song

Division of Animal and Dairy Science,

Chungnam National University,

Daejeon 34134, Korea.

Tel: +82-42-821-5776

E-mail: mhsong@cnu.ac.kr

Younghoon Kim

Department of Agricultural

Biotechnology and Research Institute of Agriculture and Life Science, Seoul

National University, Seoul 08826,

Korea.

Tel: +82-2-880-4808

E-mail: ykeys2584@snu.ac.kr

Copyright $\odot 2021$ Korean Society of Animal Sciences and Technology.

This is an Open Access article distributed under the terms of the Creative Commons Attribution Non-Commercial License (http:// creativecommons.org/licenses/by$\mathrm{nc} / 4.0 /$ ) which permits unrestricted non-commercial use, distribution, and reproduction in any medium, provided the original work is properly cited.

ORCID

Daye Mun

https://orcid.org/0000-0002-3470-7632

\section{Effects of Bacillus-based probiotics on growth performance, nutrient digestibility, and intestinal health of weaned pigs}

\author{
Daye Mun ${ }^{1 \#}$, Hyunjin Kyoung ${ }^{2 \#}$, Myunghwan Kong ${ }^{2 \#}$, Sangdon Ryu ${ }^{1}$, \\ Ki Beom Jang ${ }^{3}$, Jangryeol Baek ${ }^{2}$, Kyeong II Park ${ }^{2}$, Minho Song ${ }^{2 *}$ and \\ Younghoon $\mathrm{Kim}^{1 *}$
}

${ }^{1}$ Department of Agricultural Biotechnology and Research Institute of Agriculture and Life Science, Seoul National University, Seoul 08826, Korea

${ }^{2}$ Division of Animal and Dairy Science, Chungnam National University, Daejeon 34134, Korea

${ }^{3}$ Department of Animal Science, North Carolina State University, Raleigh, NC 2769, USA

\begin{abstract}
Bacillus is characterized by the formation of spores in harsh environments, which makes it suitable for use as a probiotic for feed because of thermostability and high survival rate, even under long-term storage. This study was conducted to investigate the effects of Bacillus-based probiotics on growth performance, nutrient digestibility, intestinal morphology, immune response, and intestinal microbiota of weaned pigs. A total of 40 weaned pigs (7.01 $\pm 0.86 \mathrm{~kg}$ body weight [BW]; $28 \mathrm{~d}$ old) were randomly assigned to two treatments (4 pigs/ pen; 5 replicates/treatment) in a randomized complete block design (block $=\mathrm{BW}$ and sex). The dietary treatment was either a typical nursery diet based on corn and soybean meal (CON) or CON supplemented with $0.01 \%$ probiotics containing a mixture of Bacillus subtilis and Bacillus licheniformis (PRO). Fecal samples were collected daily by rectal palpation for the last 3 days after a 4-day adaptation. Blood, ileal digesta, and intestinal tissue samples were collected from one pig in each pen at the respective time points. The PRO group did not affect the feed efficiency, but the average daily gain was significantly improved $(p<0.05)$. The PRO group showed a trend of improved crude protein digestibility $(p<0.10)$. The serum transforming growth factor- $\beta 1$ level tended to be higher $(p<0.10)$ in the PRO group on days 7 and 14. There was no difference in phylum level of the intestinal microbiota, but there were differences in genus composition and proportions. However, $\beta$-diversity analysis showed no statistical differences between the CON and the PRO groups. Taken together, Bacillus-based probiotics had beneficial effects on the growth performance, immune system, and intestinal microbiota of weaned pigs, suggesting that Bacillus can be utilized as a functional probiotic for weaned pigs.
\end{abstract}

Keywords: Bacillus-based probiotics, Weaned pigs, Growth performance, Immune response, Intestinal health 
Hyunjin Kyoung

https://orcid.org/0000-0001-5742-5374

Myunghwan Kong

https://orcid.org/0000-0002-7207-9382

Sangdon Ryu

https://orcid.org/0000-0001-5338-8385

Ki Beom Jang

https://orcid.org/0000-0001-6794-9569

Jangryeol Baek

https://orcid.org/0000-0002-1722-2641

Kyeong II Park

https://orcid.org/0000-0002-3590-3993

Minho Song

https://orcid.org/0000-0002-4515-5212

Younghoon Kim

https://orcid.org/0000-0001-6769-0657

Competing interests

No potential conflict of interest relevant to

this article was reported.

\section{Funding sources}

This work was supported by grants from National Agricultural Cooperative Federation

(NACF) and a grant from the Agricultural and livestock products safe distribution and consumption technology development program (Project No. 320111-1), Korea Institute of Planning and Evaluation for Technology in Food, Agriculture and Forestry (IPET), Korea and the National Research Foundation of Korea (NRF) Grant funded by the Korean government (NRF2021R1A2C3011051).

\section{Acknowledgements}

Not applicable.

Availability of data and material Upon reasonable request, the datasets of this study can be available from the corresponding author.

\section{Authors' contributions}

Conceptualization: Mun D, Kyoung H, Kong M, Song M, Kim Y.

Data curation: Mun D, Kyoung $\mathrm{H}$, Kong M, Ryu S, Jang KB, Baek J, Park KI, Song M, Kim Y.

Formal analysis: Mun D, Song M, Kim Y. Methodology: Mun D, Kyoung H, Kong M, Ryu S.

Software: Mun D, Kyoung H, Kong M, Ryu S. Validation: Jang KB, Baek J, Park KI, Song M, Kim Y.

Investigation: Mun D, Kyoung H, Kong M.

Writing - original draft: Mun D, Kyoung $\mathrm{H}$, Kong M, Song M, Kim Y.

Writing - review \& editing: Mun D, Kyoung $\mathrm{H}$, Kong M, Ryu S, Jang KB, Baek J, Park $\mathrm{KI}$, Song M, Kim Y.

Ethics approval and consent to participate The experimental protocol for this study was reviewed and approved by the Institutional Animal Care and Use Committee of Chungnam National University, Daejeon, Korea (approval \#CNU-00910).

\section{INTRODUCTION}

Weaning is a stressful period for young pigs because several stressors including separation from mother sow, diet form change, and environmental changes [1]. In addition, weaned pigs must acclimatize to less digestible plant-based solid feed rather than easily digestible sow milk [2]. These multiple stress factors cause loss of appetite, which leads to insufficient energy intake for the maintenance of gastrointestinal health [3]. Additionally, the damage of intestinal epithelial layers because of weaning stress reduces trans-mucosal resistance [2]. Therefore, piglets in the weaning period are sensitive to infection by enteric pathogens, such as Escherichia coli, which leads to diarrhea $[4,5]$.

To prevent post-weaning diarrhea and to improve growth performance and gut health of piglets, various antibiotics have been used as growth promoters [6,7]. However, because of potential safety issues, such as antimicrobial resistance or antibiotic residue, that may occur when antibiotics are overused, most countries have banned the use of antibiotics as growth promoters [8,9]. Therefore, a number of studies are being conducted to develop powerful alternatives to antibiotics for maintaining the health of weaned pigs [10].

Probiotics are defined by the FAO/WHO group as "live microorganisms which, when administered in adequate amounts, confer a good health benefit on the host" [11,12]. It has been well studied that probiotics could be alternatives to antibiotics because of their ability to reduce diarrhea and improve the growth performance of weaned pigs [13]. General strains of probiotic spices are mostly isolated from consumers of probiotics, including humans, chickens, or pigs. Commonly, Bacillus, Lactobacillus, Bifidobacterium, Enterococcus, and Streptococcus are used as probiotics [11]. Among them, Bacillus is an attractive bacterium for administration as a probiotic in swine feed because of its ability to form spores, which allows the bacterium to withstand hightemperature and the low-pH of gastric juices [14]. Additionally, spore-forming bacteria, such as Bacillus subtilis and Bacillus amyloliquefaciens, allow for long-term storage without losing viability [15]. According to previous studies, supplementation of Bacillus has been shown to improve growth performance by enhancing gut barrier integrity and relieving post-weaning diarrhea $[14,16]$.

Although several previous studies have shown that Bacillus has beneficial properties for the host, the results of its effects on the immune system or intestinal microbiota of weaned pigs are still inconsistent. Therefore, this study was conducted to investigate the effect of Bacillus-based probiotics on growth performance, nutrient digestibility, intestinal morphology, immune response and intestinal microbiota of weaned pigs.

\section{MATERIALS AND METHODS}

\section{Experimental design, animals, and diets}

The procedure of experiment was reviewed and approved by the Institutional Animal Care and Use Committee of Chungnam National University, Daejeon, Korea (approval \#CNU-00910). This study was carried out at the facility of Animal Research Center of Chungnam National University. A total of healthy 40 weaned pigs ([Landrace $\times$ Yorkshire $] \times$ Duroc; $7.01 \pm 0.86 \mathrm{~kg} ; 28 \mathrm{~d}$ old) were assigned to 2 treatments in a randomized complete block design (block = body weight [BW] and sex) with 4 pigs per pen and 5 replicated pens per treatment. The dietary treatment was either a typical nursery diet based on corn and soybean meal $(\mathrm{CON})$ or $\mathrm{CON}$ supplemented with $0.01 \%$ probiotics (PRO). Both dietary treatments were formulated to meet or exceed the requirements of the National Research Council [17] of weaned pigs and to have comparable metabolizable energy, crude protein (CP), and lysine levels (Table 1). Animal plasma, antibiotics, and zinc 
Table 1. Composition of experimental diet for weaning pigs (as-fed basis)

\begin{tabular}{lc}
\hline \multicolumn{1}{c}{ Items } & Weaner \\
\hline Ingredients (\%) & \\
Corn & 49.86 \\
Whey powder & 12.50 \\
Soybean meal (44\%) & 25.00 \\
Soy protein concentrate & 6.25 \\
Soybean oil & 3.00 \\
Limestone & 1.14 \\
Mono-calcium phosphate & 1.05 \\
Vitamin premix ${ }^{1)}$ & 0.20 \\
Mineral premix & 0.20 \\
L-Lysine-HCl & 0.45 \\
DL-Methionine & 0.16 \\
L-Threonine & 0.13 \\
L-Valine & 0.06 \\
Calculated energy and nutrient contents & \\
Metabolizable energy (kcal/kg) & 3,465 \\
Crude protein (\%) & 21.26 \\
Calcium (\%) & 0.81 \\
Phosphorus (\%) & 0.65 \\
\hline
\end{tabular}

${ }^{11}$ Provided per kilogram of complete diet: vitamin A, 12,000 IU; vitamin $\mathrm{D}_{3}, 2,500 \mathrm{IU}$; vitamin E, $30 \mathrm{IU}$; vitamin $\mathrm{K}_{3}, 3 \mathrm{mg}$; D-pantothenic acid, $15 \mathrm{mg}$; nicotinic acid, $40 \mathrm{mg}$; choline, $400 \mathrm{mg}$; vitamin $\mathrm{B}_{12}, 12 \mu \mathrm{g}$.

${ }^{2)}$ Provided per kilogram of complete diet: $\mathrm{Fe}, 90 \mathrm{mg}$ from iron sulfate; $\mathrm{Cu}, 8.8 \mathrm{mg}$ from copper sulfate; $\mathrm{Zn}, 100 \mathrm{mg}$ from zinc oxide; $\mathrm{Mn}, 54 \mathrm{mg}$ from manganese oxide; l, $0.35 \mathrm{mg}$ from potassium iodide; $\mathrm{Se}, 0.30 \mathrm{mg}$ from sodium selenite.

oxide were excluded from the piglet diets to avoid antimicrobial or physiological effects, and all feeds were provided in meal form. The dietary probiotics used in this study were a commercial product containing a mixture of Bacillus subtilis and Bacillus licheniformis. Pigs were housed in an environmentally controlled room and each pen was equipped with a feeder and water. Also, piglets were allowed ad libitum access to feed and water throughout the experiment.

\section{Data and sample collection}

The BW of pigs was recorded at $\mathrm{d} 0$ of the experiment and at the last day of the experiment. The amount of feed added per pen was recorded, and feed residue were weighed from each pen on the last day of the experiment. The difference between the last BW and the initial BW was divided by the number of experimental days to determine the average daily gain (ADG). The feed intake per piglet was divided by the number of experimental days and was determined as the average daily feed intake (ADFI). To obtain the feed efficiency, the gain to feed ratio (G:F) was calculated by dividing ADG by ADFI for each pen. Diarrhea scores of all piglets during the experiment were recorded daily for 2 weeks from the first day after weaning. The diarrhea score for each pig was visually assessed daily on a scale of 1 to $5(1=$ dry feces, $2=$ normal feces, $3=$ slightly moist feces, 4 $=$ semiliquid feces, mild diarrhea, and $5=$ watery feces, severe diarrhea). The frequency of diarrhea (\%) was calculated by counting the number of days the pigs had a diarrhea score of 4 or greater [18]. Whole blood samples were collected from one randomly selected pig in each pen using the jugular vein and stored in ethylenediaminetetraacetic acid tubes with anticoagulant or serum tubes (Becton Dickinson Vacutainer Systems, Franklin Lakes, NJ, USA) to measure total white blood cells (WBC) counts or inflammatory cytokines on $\mathrm{d} 7$ and 14. Pigs were each fed a dietary 
treatment containing $0.2 \%$ indigestible chromium oxide during the last week of the experimental period to determine the apparent ileal and total tract digestibility of nutrients. For the collection of fresh fecal samples, rectal palpation was performed from one randomly selected pig in each pen for the last 3 days after the 4-day adjustment period. The collected stool samples and diet samples were stored at $-20^{\circ} \mathrm{C}$ until analysis. Fecal samples for metagenome analysis were freshly collected from three randomly selected pigs in each treatment group on the last day of the experiment by rectal palpation with a sterile cotton swab, and the samples were placed in a sterile tube. The samples were taken to the laboratory on ice and stored at $-80^{\circ} \mathrm{C}$ in a deep freezer until further analysis. On the last day of the experiment, one randomly selected piglet in each pen was anesthetized using 2 $\mathrm{mL}$ of suxamethonium chloride (Succicholine ${ }^{\circledR}$, Ilsung Pharm, Seoul, Korea) by an intramuscular injection. Immediately after anesthesia, pigs were euthanized by $\mathrm{CO}_{2}$ gas [19]. Digesta samples of the pig gastrointestinal tract were collected from the terminal ileum before the ileocecal valve and were stored at $-20^{\circ} \mathrm{C}$ until the time of analysis. For histological analysis, $3-\mathrm{cm}$ sections were taken from the middle of the duodenum, jejunum, and ileum. The tissue samples were gently flushed with $0.05 \mathrm{M}$ phosphate buffered saline ( $\mathrm{pH} 7.2)$ and were then fixed in $10 \%$ neutral buffered formalin.

\section{Sample measurements and analysis}

Before chemical analysis, frozen ileal digesta, fecal samples, and feed samples were thawed, dried at $60^{\circ} \mathrm{C}$ for $72 \mathrm{~h}$ and finely ground. Dry matter (DM, method 930.15) and nitrogen (method 999.03) of all samples were analyzed according to the procedures outlined in the Association of Official Analytical Chemists [20]. The gross energy (GE) was analyzed for each sample using a bomb calorimeter (Parr 1281 Bomb Calorimeter, Parr Instrument, Moline, IL, USA), and nitrogen was measured using a Kjeltec 2300 Analyzer (Foss Tecator AB, Hoeganaes, Sweden). Chromium levels in the samples were measured by UV spectrophotometer (Hitachi Z-5000, Hitachi HighTechnologies, Tokyo, Japan). The apparent total tract digestibility (ATTD) and apparent ileal digestibility (AID) of the DM, CP, and GE were calculated for each sample as described by Stein et al. [21]. The fixed tissue samples taken from the small intestine were embedded in paraffin wax, sectioned to $5 \mu \mathrm{m}$ using a microtome, and stained with hematoxylin and eosin. Stained sections were examined using a charge-coupled device camera-equipped microscope (TE2000, Nikon, Tokyo, Japan) with digital imaging software for measurements and counts (NIS Elements BR; Nikon). The 15 longest and straightest villi and their associated crypts were selected to evaluate morphological changes [22]. The morphometric measurements of intestinal tissue were carried out as follows: villus height; crypt depth; villus height to crypt depth ratio (VH:CD); and the number of goblet cells. Whole blood samples were analyzed by an automated hematology analyzer (scil Vet abc hematology analyzer; scil animal care company,Viernheim, Germany) calibrated for porcine blood for total WBC counts. The blood samples for serum were allowed to clot for $2 \mathrm{~h}$ at room temperature and then overnight at $4{ }^{\circ} \mathrm{C}$ followed by centrifugation at 3,000×g for $15 \mathrm{~min}$ at $4^{\circ} \mathrm{C}$. Serum concentrations of cytokines and cortisol were measured by using a porcine-specific tumor necrosis factor- $\alpha$ (TNF- $\alpha$ ) or transforming growth factor- $\beta 1$ (TGF- $\beta 1$ ) ELISA kit (R\&D Systems, Minneapolis, MN,USA), a porcine-specific cortisol ELISA kit (Cusabio, Wuhan, China), a porcine C-reactive protein or an immunoglobulin ELISA kit (Abnova, Taipei City, Taiwan), and measurements were conducted according to the manufacturer's protocols. The optical density was measured at $450 \mathrm{~nm}$, and all concentrations were calculated using a standard curve.

DNA extraction, amplification, and sequencing

DNA was extracted from fecal samples using a PowerSoil DNA Isolation kit (MO BIO Laboratories, Carlsbad, CA, USA) according to the manufacturer's protocol. DNA concentration 
and quality were determined by measuring absorbance at 230, 260, and $280 \mathrm{~nm}$ using a spectrophotometer (SpectraMax ABS Plus, Molecular Devices, San Jose, CA, USA). To amplify the V4 region from the $16 \mathrm{~S}$ rRNA gene, 341F/805R primers (forward, 5'-CCT ACG GGN GGC WGC AG-3'; reverse, 5'-GAC TAC HVG GGT ATC TAA TCC-3') were used. 16S rRNA gene amplicon sequencing was performed on the Illumina MiSeq platform at Macrogen (Seoul, Korea).

\section{Metagenomic analysis}

The raw paired-end reads were processed using Quantitative Insights Into Microbial Ecology 2 (QI- IME2; version 2020.6.0). Quality control (e.g., filtering, trimming the sequence and removing chimeric sequences) was performed on demultiplexed sequences with the DADA2 pipeline. Taxonomic assignment was performed with the Greengenes reference database (13_8 version) into operational taxonomic units (OTUs) with $97 \%$ similarity. To assess within-sample diversity, microbial $\alpha$-diversity was calculated based on several metrics (Shannon, Chao1, and Simpson index) with the script "diversity $\alpha$-group-significance" after making phylogenetic trees using the mafft and FastTree programs of QIIME2. To evaluate between-group diversity, $\beta$-diversity using phylogenetic-based weight and unweighted UniFrac distances were measured through the script "diversity beta-group-significance". Additionally, based on the weight and unweighted UniFrac distance metrics, principal coordinate analysis $(\mathrm{PCoA})$ plots were used to visualize $\beta$-diversity.

\section{Statistical analyses}

The PROC GLM procedures of SAS (SAS Inst., Cary, NC, USA) were used to analyze all data except frequency of diarrhea and fecal microbiota in a randomized complete block design, and the experimental unit was the pen. The statistical model for growth performance, nutrient digestibility, intestinal morphology, and immune responses of piglets included effects of dietary treatment as a fixed effect. The results are presented as the mean \pm standard error of the mean. A chi-squared test was used for the diarrhea frequency. Statistical analysis of the fecal microbial composition was performed using QIIME2 and GraphPad Prism software version 7 (La Jolla, CA, USA). Permutational multivariate analysis of variance (PERMANOVA) was performed using QIIME2 to establish whether the profile of fecal microbiota between the two groups was significantly different and was based on UniFrac distance matrices. Statistical significance and tendency were considered at $p<0.05$ and $0.05 \leq p<0.10$, respectively.

\section{RESULTS AND DISCUSSION}

\section{Growth performance and nutrient digestibility}

Weaned pigs fed PRO had significantly improved ADG (428.57 vs. $386.19 \mathrm{~g} / \mathrm{d} ; p<0.05$ ) (Table 2). There were no significant differences in ADFI, G:F, and frequency of diarrhea between CON and PRO. Additionally, as shown in Table 3, there were no differences in the AID of DM, CP, and GE and the ATTD of DM and GE between CON and PRO at the end of the experiment. Pigs fed PRO tended to have improved ATTD of CP (87.25\% vs. 84.13\%; $p<0.10)$. Several studies have shown that the addition of Bacillus to pig feed could improve growth performance or reduce the incidence of diarrhea $[16,23]$. However, some previous studies failed to observe such positive effects on growth performance [24-26]. These discrepancies in the effect of Bacillus on pig growth performance may be caused by various factors, such as diet formula, different Bacillus species, dose, pig age, or environmental features [15]. In this study, the AID of DM, CP, and GE and the ATTD of either DM or GE were not affected by Bacillus-based probiotics. However, pigs supplemented with Bacillus-based probiotics tended to show improved ATTD of CP. Based on these results, it can 
Table 2. Effects of Bacillus-based probiotics on overall growth performance of weaned pigs ${ }^{1)}$

\begin{tabular}{|c|c|c|c|c|}
\hline \multirow{2}{*}{ Item } & \multicolumn{2}{|c|}{ Dietary treatments } & \multirow{2}{*}{ SEM } & \multirow{2}{*}{$p$-value } \\
\hline & CON & PRO & & \\
\hline Initial BW (kg) & 7.01 & 7.02 & 0.41 & 0.917 \\
\hline Final BW (kg) & 23.23 & 25.02 & 0.81 & 0.155 \\
\hline Feed intake (kg) & 27.59 & 29.66 & 1.83 & 0.491 \\
\hline $\operatorname{ADG}(g / d)$ & 386.19 & 428.57 & 11.85 & 0.040 \\
\hline $\operatorname{ADFI}(g / d)$ & 656.90 & 706.19 & 43.58 & 0.491 \\
\hline $\mathrm{G}: F(g / g)$ & 0.588 & 0.607 & 0.03 & 0.739 \\
\hline Frequency of diarrhea $(\%)^{2)}$ & 14.29 & 13.27 & & 0.845 \\
\hline
\end{tabular}

${ }^{11}$ Each value presented as the least square mean of 5 replicates (4 pigs/pen).

${ }^{2}$ Frequency of diarrhea $(\%)=($ Number of pigs with diarrhea / number of pen days $) \times 100$. The data was analyzed by chisquared test.

CON, control diet based on soy-bean meal diet; PRO, control + 0.01\% Bacillus-based probiotics; BW, body weight; ADG, average daily gain; $A D F I$, average daily feed intake; G:F, gain-to-feed ratio.

Table 3. Effects of Bacillus-based probiotics on nutrient digestibility of weaned pigs ${ }^{1 /}$

\begin{tabular}{|c|c|c|c|c|}
\hline \multirow{2}{*}{ Item } & \multicolumn{2}{|c|}{ Dietary treatments } & \multirow{2}{*}{ SEM } & \multirow{2}{*}{$p$-value } \\
\hline & CON & PRO & & \\
\hline \multicolumn{5}{|c|}{ Apparent ileal digestibility (\%) } \\
\hline DM & 84.11 & 85.18 & 3.201 & 0.877 \\
\hline $\mathrm{CP}$ & 80.78 & 80.99 & 3.949 & 0.872 \\
\hline GE & 83.36 & 83.86 & 3.233 & 0.865 \\
\hline \multicolumn{5}{|c|}{ Apparent total tract digestibility (\%) } \\
\hline DM & 87.48 & 86.36 & 1.127 & 0.500 \\
\hline $\mathrm{CP}$ & 84.13 & 87.25 & 1.155 & 0.067 \\
\hline GE & 87.15 & 86.22 & 1.141 & 0.577 \\
\hline
\end{tabular}

${ }^{1)}$ Each value presented as the least square mean of 5 replicates.

CON, control diet based on soy-bean meal diet; PRO, control + 0.01\% Bacillus-based probiotics; DM, dry matter; CP, crude protein; GE, gross energy.

be speculated that improved growth rate of pigs may be a result of a tendency to increase ATTD in CP. Similarly, some previous studies demonstrated that pigs supplemented with Bacillus-based probiotics showed improved nutrient digestibility [27,28]. One of the major well-known benefits of Bacillus spp. is to eliminate pathogens through nutrient competition in the intestinal mucosa, thereby increasing the balance of host gut microbiota and maximizing nutrient utilization [29,30]. Additionally, Bacillus spp. can synthesize various types of extracellular enzymes and proteases $[31,32]$. Therefore, it is predicted that nutrient digestibility may be increased due to Bacillus-based probiotic supplements in feed.

\section{Intestinal morphology}

Weaning leads to reduction of $\mathrm{VH}$ and $\mathrm{VH}: \mathrm{CD}$, impaired intestinal barrier function, and decreased mucin levels [2,3]. Intestinal epithelium cells play an important role in digestion, nutrient absorption, and protection from pathogens and toxins in the gastrointestinal tract [33,34]. Therefore, analyzing the morphology of the intestine is a profitable indicator for assessing the health and function of the intestine [35]. The goblet cells at the intestinal mucus layer produce secretory mucin glycoproteins or membrane-bound mucins, the proteins that form the mucus layer that acts as a line of defense against enteric pathogens and microbial adhesion and invasion [36,37]. 
In this study, the effects of Bacillus-based probiotics on the intestinal morphology of the small intestine (duodenum, jejunum, and ileum) and the number of goblet cells were evaluated (Table 4). Bacillus-based probiotics did not affect the intestinal morphology in the duodenum, jejunum, and ileum, but tended to increase the number of goblet cells in the ileum (16.91 vs. 10.83; $p<0.10)$. Similarly, several studies reported that small intestinal morphology was not affected by probiotic products [38-40]. However, other studies have demonstrated a positive effect on intestinal histomorphology in pigs that consume Bacillus-based probiotics [37,41,42]. The inconsistent results may be because of different strains or levels of probiotics and the overall health of the pigs.

\section{Immune response}

Probiotics are well known to regulate the production of lymphocyte cytokines and have a major effect on the immune system [43]. To investigate the effects of Bacillus-based probiotics on the immune systems of piglets, blood parameters were analyzed, including the number of WBC and serum cytokines. As shown in Table 5, the blood parameters were not significantly different between CON and PRO. The TGF- $\beta 1$ in the serum tended to be higher in the probiotic group at $\mathrm{d} 7(987.28$ vs. $590.85 \mathrm{pg} / \mathrm{mL} ; p<0.10)$ and $\mathrm{d} 14(1,095.56$ vs. $636.03 \mathrm{pg} / \mathrm{mL} ; p<0.10)$. The TGF- $\beta 1$ is an anti-inflammatory cytokine that is known to maintain intestinal epithelial integrity and support the differentiation of immature dendritic cells [44]. According to a previous study, administration of a probiotic mixture (Bacillus licheniformis and Bacillus subtilis) increased the expression of mRNA for the gene encoding TGF- $\beta 1$ in ileum tissues of weaned pigs [45]. Multimicrobial probiotics also increased TGF- $\beta$ concentration in the serum of sows [46]. The TNF- $\alpha$ is a pro-inflammatory cytokine that activates the secretion of other cytokines, macrophages, and neutrophils [47]. In addition, it plays an important role in the initial immune response by stimulating immature immune cells to become mature cells and enhancing the antigen-killing ability of these cells $[48,49]$. Previous studies have reported that feeding a probiotic mixture

Table 4. Effects of Bacillus-based probiotics on intestinal morphology of weaned pigs ${ }^{1)}$

\begin{tabular}{|c|c|c|c|c|}
\hline \multirow{2}{*}{ Item } & \multicolumn{2}{|c|}{ Dietary treatments } & \multirow{2}{*}{ SEM } & \multirow{2}{*}{$p$-value } \\
\hline & CON & PRO & & \\
\hline \multicolumn{5}{|l|}{ Duodenum } \\
\hline $\mathrm{VH}(\mu \mathrm{m})$ & 269.78 & 286.78 & 10.30 & 0.270 \\
\hline $\mathrm{CD}(\mu \mathrm{m})$ & 120.98 & 122.11 & 5.04 & 0.877 \\
\hline $\mathrm{VH}: \mathrm{CD}$ & 2.23 & 2.35 & 0.08 & 0.309 \\
\hline Number of goblet cells ( $n$ ) & 6.10 & 5.85 & 0.98 & 0.858 \\
\hline \multicolumn{5}{|l|}{ Jejunum } \\
\hline $\mathrm{VH}(\mu \mathrm{m})$ & 309.71 & 279.90 & 15.76 & 0.211 \\
\hline $\mathrm{CD}(\mu \mathrm{m})$ & 143.37 & 131.24 & 8.54 & 0.339 \\
\hline $\mathrm{VH}: \mathrm{CD}$ & 2.16 & 2.13 & 0.11 & 0.911 \\
\hline Number of goblet cells ( $n$ ) & 5.07 & 5.77 & 0.80 & 0.548 \\
\hline \multicolumn{5}{|l|}{ lleum } \\
\hline $\mathrm{VH}(\mu \mathrm{m})$ & 271.84 & 279.14 & 18.82 & 0.789 \\
\hline $\mathrm{CD}(\mu \mathrm{m})$ & 123.62 & 121.60 & 6.96 & 0.842 \\
\hline $\mathrm{VH}: \mathrm{CD}$ & 2.20 & 2.30 & 0.16 & 0.675 \\
\hline Number of goblet cells ( $n$ ) & 10.83 & 16.91 & 2.38 & 0.091 \\
\hline
\end{tabular}

${ }^{1)}$ Each value presented as the least square mean of 5 replicates.

CON, control diet based on soy-bean meal diet; PRO, control $+0.01 \%$ Bacillus-based probiotics; VH, villus height; CD, crypt depth. 
Table 5. Effects of Bacillus-based probiotics on immune responses of weaned pigs ${ }^{1)}$

\begin{tabular}{|c|c|c|c|c|}
\hline \multirow{2}{*}{ Item } & \multicolumn{2}{|c|}{ Dietary treatments } & \multirow{2}{*}{ SEM } & \multirow{2}{*}{$p$-value } \\
\hline & CON & PRO & & \\
\hline \multicolumn{5}{|l|}{ Day 7} \\
\hline Number of white blood cells $\left(\times 10^{3} / \mu \mathrm{L}\right)$ & 17.47 & 17.92 & 2.277 & 0.892 \\
\hline $\mathrm{CRP}(\mathrm{ng} / \mathrm{mL})$ & 152.98 & 282.30 & 56.45 & 0.167 \\
\hline Cortisol (ng/mL) & 1.21 & 2.47 & 0.56 & 0.172 \\
\hline TGF- $\beta 1(p g / m L)$ & 590.85 & 987.28 & 139.03 & 0.092 \\
\hline TNF- $\alpha(p g / m L)$ & 317.94 & 366.82 & 17.98 & 0.079 \\
\hline $\lg A(n g / m L)$ & 72.17 & 66.71 & 5.89 & 0.527 \\
\hline $\lg \mathrm{g}(\mathrm{ng} / \mathrm{mL})$ & 945.69 & 943.74 & 13.29 & 0.919 \\
\hline $\operatorname{lgM}(\mathrm{ng} / \mathrm{mL})$ & 234.02 & 199.70 & 43.52 & 0.589 \\
\hline \multicolumn{5}{|l|}{ Day 14} \\
\hline Number of white blood cells $\left(\times 10^{3} / \mu \mathrm{L}\right)$ & 20.32 & 20.13 & 2.113 & 0.952 \\
\hline $\mathrm{CRP}(\mathrm{ng} / \mathrm{mL})$ & 149.88 & 191.47 & 43.33 & 0.529 \\
\hline Cortisol (ng/mL) & 1.44 & 2.02 & 0.40 & 0.353 \\
\hline TGF- $\beta 1$ (pg/mL) & 636.03 & $1,095.56$ & 153.67 & 0.089 \\
\hline TNF- $\alpha(p g / m L)$ & 341.43 & 386.42 & 17.47 & 0.903 \\
\hline $\lg \mathrm{A}(\mathrm{ng} / \mathrm{mL})$ & 88.17 & 80.53 & 9.59 & 0.586 \\
\hline $\lg G(\mathrm{ng} / \mathrm{mL})$ & 972.57 & 956.67 & 17.79 & 0.251 \\
\hline $\operatorname{lgM}(\mathrm{ng} / \mathrm{mL})$ & 161.92 & 182.53 & 26.49 & 0.594 \\
\hline
\end{tabular}

${ }^{1)}$ Each value presented as the least square mean of 5 replicates.

CON, control diet based on soy-bean meal diet; PRO, control + 0.01\% Bacillus-based probiotics; CRP, C-reactive protein; TGF- $\beta 1$, transforming growth factor- $\beta 1$; TNF- $\alpha$, tumor necrosis factor- $\alpha$; IgA, immunoglobulin A; IgG, immunoglobulin G; IgM, immunoglobulin $\mathrm{M}$.

(Bacillus licheniformis and Bacillus subtilis) increased the mRNA expression of TNF- $\alpha$, but did not show a significant change in the concentration of TNF- $\alpha$ in the serum of weaned pigs [45]. Similarly, in the current study, the concentration of TNF- $\alpha$ in the serum of the probiotic group tended to be higher on $\mathrm{d} 7$ (366.82 vs. $317.94 \mathrm{pg} / \mathrm{mL} ; p<0.10$ ), but the difference between the two groups disappeared on d 14 (386.42 vs. $341.43 \mathrm{pg} / \mathrm{mL} ; p=0.903$ ). However, there was no significant difference between the two groups in the overall immunity index, which may be due to the minimal immune response of weaned pigs under good hygienic experimental conditions [28]. Consistent with this result, it was previously shown that the treatment with multi-strain probiotics had no effect on immune markers [50].

\section{$16 S$ rRNA sequencing data and fecal microbial composition}

To investigate the effect of Bacillus-based probiotics on microbial composition, taxonomic analysis was performed. A total of 6 fecal samples yielded a total of 233,408 reads in this study, and the number of sequence reads ranged from 35,128 to 49,995 (mean $=38,901$; median $=37,070$ ). After quality control and removal of chimeras in OIIME2, the sequences were clustered into 1,799 OTUs based on $97 \%$ identity in our fecal samples. The relative abundances of the fecal microbiota of the control and probiotic groups at the phylum and genus levels are shown in Fig. 1. At the phylum level, the bacterial composition of the CON group on the last day of the experiment was predominated by the phyla Firmicutes (74.38\%), Bacteroidetes (18.38\%), and Spirochaetes (1.18\%). Other phyla with relative abundances lower than $1 \%$ were Proteobacteria, Spirochaetes, Actinobacteria, and Tenericutes. By comparison, the core fecal microbiota at the phylum level of the probiotic group was Firmicutes (74.76\%), Bacteroidetes (15.28\%), Proteobacteria (1.63\%), 
A

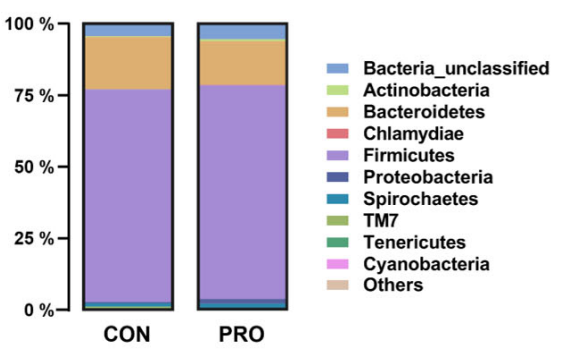

B

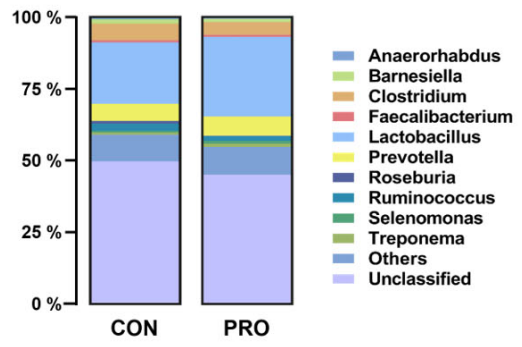

Fig. 1. Effects of Bacillus-based probiotics on fecal microbial composition of weaned pigs. Relative abundance of fecal microbial taxa at the phylum level (A) and genus level (B) of both groups. CON, control diet based on soy-bean meal diet; PRO, control $+0.01 \%$ Bacillus-based probiotics.

and Spirochaetes (1.5\%). The low-abundance $(<1 \%)$ phyla were Actinobacteria, Chlamydiae, and Cyanobacteria. The abundances of unclassified bacteria from the fecal microbiota of the CON and PRO groups were $4.40 \%$ and 5.34\%, respectively. A total of 107 genera were classified from all six samples at the genus level. The major genera of the CON group were Lactobacillus (21.50\%), Prevotella (5.98\%), Clostridium (5.91\%), Ruminococcus (2.57\%), Barnesiella (1.59\%), and Roseburia (1.04\%). Furthermore, the predominant taxa at the genus level of the PRO group were Lactobacillus (27.77\%), Prevotella (6.71\%), Clostridium (4.51\%), Ruminococcus (1.71\%), Barnesiella (1.13\%), Treponema (1.17\%), and Selenomonas (1.04\%). The abundance of unclassified genera in each group was $49.26 \%$ and $44.75 \%$, respectively. Intestinal microbes have various functions, such as the production of volatile fatty acids and vitamin $\mathrm{K}$, digestion of cellulose, and regulation of the immune system. Because these functions are closely related to the gut health of pigs, they have been a major issue in recent years. $[1,8]$. Our findings show that, as in previous studies, Firmicutes and Bacteroidetes in fecal samples accounted for more than $90 \%$ of the phyla in both the CON and PRO groups [51,52]. Most unclassified genera belong to the Ruminococcaceae family, which is known to play a beneficial role in gut health by breaking down various polysaccharides and fibers and producing short-chain fatty acids [53,54]. The most dominant genera at the genus level in both the CON and PRO groups were Prevotella and Lactobacillus. Since weaned pigs generally consume grain-based carbohydrate-rich feed, it is presumed that Prevotella and Lactobacillus, which are involved in the fermentation of non-starch polysaccharides and the production of short-chain fatty acids, are dominated $[55,56]$.

\section{Fecal microbial diversity analysis}

To determine microbial richness and evenness, Chao1, Shannon, and Simpson indices were calculated. The alpha diversity did not differ between the control and probiotic groups (Figs. 2A, B, and $\mathrm{C}$, respectively). To compare the microbial diversity of fecal samples between the two groups, beta diversity was analyzed. PERMANOVA of weighted UniFrac distances showed that there was no remarkable difference between the two groups in microbial diversity (Fig. 2D). The PCoA based on unweighted UniFrac distances also indicated that there were no significant differences between the CON and PRO groups (Fig. 2E). A previous study showed that when Bacillus subtilis was fed to weaned pigs, there was no change in the alpha diversity of the small intestinal microbiota, but the microbial composition of the ileum and jejunum contents differed between the control and probiotic groups [57]. In addition, supplementing the feed with B. subtilis and/or yeast cultures did not affect the richness or diversity of feces from weaned pigs compared to the control group [58]. It was also reported that feeding weaned pigs higher doses of B. subtilis did not change the 
A

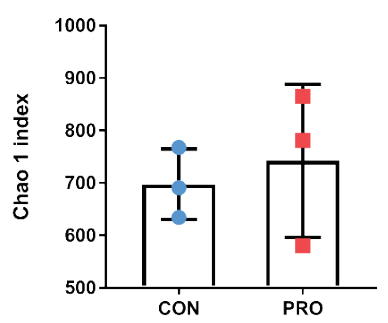

D

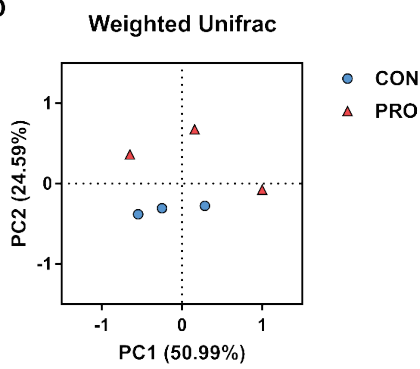

B

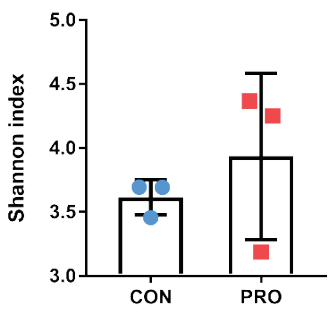

E

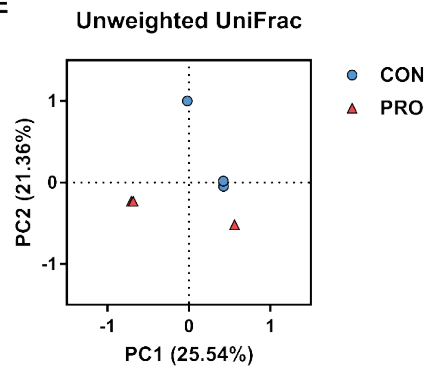

Fig. 2. Effects of probiotics on fecal microbial diversity of weaned pigs. Alpha diversity determined by the Chao 1 (A), Shannon (B), and Simpson (C) index. PCoA plot based on weighted UniFrac (D) and unweighted UniFrac (E) distances. CON, control diet based on soy-bean meal diet; PRO, control $+0.01 \%$ Bacillus-based probiotics; PC, principal component.

alpha diversity compared to the control group but caused a distinct separation between groups [41]. Additional studies are needed for various doses and strains of Bacillus-based probiotics that cause clear changes in the intestinal microbiota between groups.

\section{CONCLUSION}

The addition of Bacillus-based probiotics has beneficial effects on the growth performance including ADG and modulates immune system and gut microbiota of weaned pigs, suggesting that Bacillus could be utilized as a functional probiotic in animal feed. However, further study is needed to assess the effects of different Bacillus species and doses on the growth performance and intestinal health of weaned pigs and to evaluate the mechanism of action.

\section{REFERENCES}

1. Lallès JP, Bosi P, Smidt H, Stokes CR. Nutritional management of gut health in pigs around weaning. Proc Nutr Soc. 2007;66:260-8. https://doi.org/10.1017/S0029665107005484

2. Pluske JR, Hampson DJ, Williams IH. Factors influencing the structure and function of the small intestine in the weaned pig: a review. Livest Prod Sci. 1997;51:215-36. https://doi. org/10.1016/S0301-6226(97)00057-2

3. Kim JC, Hansen CF, Mullan BP, Pluske JR. Nutrition and pathology of weaner pigs: nutritional strategies to support barrier function in the gastrointestinal tract. Anim Feed Sci Technol. 2012;173:3-16. https://doi.org/10.1016/j.anifeedsci.2011.12.022

4. Krause DO, Bhandari SK, House JD, Nyachoti CM. Response of nursery pigs to a synbiotic preparation of starch and an anti-Escherichia coli K88 probiotic. Appl Environ Microbiol. 2010;76:8192-200. https://doi.org/10.1128/AEM.01427-10 
5. Dlamini Z, Langa RLS, Aiyegoro OA, Okoh AI. Effects of probiotics on growth performance, blood parameters, and antibody stimulation in piglets. S Afr J Anim Sci. 2017;47:766-75. https://doi.org/10.4314/sajas.v47i6.4

6. Pettigrew JE. Reduced use of antibiotic growth promoters in diets fed to weanling pigs: dietary tools, part 1. Anim Biotechnol. 2006;17:207-15. https://doi.org/10.1080/10495390600956946

7. Stein HH, Kil DY. Reduced use of antibiotic growth promoters in diets fed to weanling pigs: dietary tools, part 2. Anim Biotechnol. 2006;17:217-31. https://doi.org/10.1080/10495390600 957191

8. Heo JM, Opapeju FO, Pluske JR, Kim JC, Hampson DJ, Nyachoti CM. Gastrointestinal health and function in weaned pigs: a review of feeding strategies to control post-weaning diarrhoea without using in-feed antimicrobial compounds. J Anim Physiol Anim Nutr. 2013;97:207-37. https://doi.org/10.1111/j.1439-0396.2012.01284.x

9. Lee JS, Kim TH, Song MH, Oh HJ, Yun W, Lee JH, et al. Effects of microencapsulated organic acids on growth performance, nutrient digestibility, fecal microbial counts, and blood profiles in weaning pigs. J Anim Sci Technol. 2021;63:104-13. https://doi.org/10.5187/jast.2021. e16

10. de Lange CFM, Pluske J, Gong J, Nyachoti CM. Strategic use of feed ingredients and feed additives to stimulate gut health and development in young pigs. Livest Sci. 2010;134:124-34. https://doi.org/10.1016/j.livsci.2010.06.117

11. Liao SF, Nyachoti M. Using probiotics to improve swine gut health and nutrient utilization. Anim Nutr. 2017;3:331-43. https://doi.org/10.1016/j.aninu.2017.06.007

12. Min Y, Choi Y, Choe J, Kim Y, Jeong Y, Kim D, et al. Effects of dietary mixture of protease and probiotics on growth performance, blood constituents, and carcass characteristics of growing-finishing pigs. J Anim Sci Technol. 2019;61:272-7. https://doi.org/10.5187/ jast.2019.61.5.272

13. Kang J, Lee JJ, Cho JH, Choe J, Kyoung H, Kim SH, et al. Effects of dietary inactivated probiotics on growth performance and immune responses of weaned pigs. J Anim Sci Technol. 2021;63:520-30. https://doi.org/10.5187/jast.2021.e44

14. He Y, Kim K, Kovanda L, Jinno C, Song M, Chase J, et al. Bacillus subtilis: a potential growth promoter in weaned pigs in comparison to carbadox. J Anim Sci. 2020;98:skaa290. https://doi. org/10.1093/jas/skaa290

15. Mingmongkolchai S, Panbangred W. Bacillus probiotics: an alternative to antibiotics for livestock production.J Appl Microbiol. 2018;124:1334-46. https://doi.org/10.1111/jam.13690

16. Hu Y, Dun Y, Li S, Zhao S, Peng N, Liang Y. Effects of Bacillus subtilis KN-42 on growth performance, diarrhea and faecal bacterial flora of weaned piglets. Asian-Australas J Anim Sci. 2014;27:1131-40. https://doi.org/10.5713/ajas.2013.13737

17. NRC [National Research Council]. Nutrient requirements of swine. 11th ed. Washington, DC: National Academy Press; 2012.

18. Lee JJ, Kyoung H, Cho JH, Choe J, Kim Y, Liu Y, et al. Dietary yeast cell wall improves growth performance and prevents of diarrhea of weaned pigs by enhancing gut health and anti-inflammatory immune responses. Animals. 2021;11:2269. https://doi.org/10.3390/ani11082269

19. Park S, Lee JJ, Yang BM, Cho JH, Kim S, Kang J, et al. Dietary protease improves growth performance, nutrient digestibility, and intestinal morphology of weaned pigs. J Anim Sci Technol. 2020;62:21-30. https://doi.org/10.5187/jast.2020.62.1.21

20. AOAC [Association of Official Analytical Chemists] International. Official methods of analysis of AOAC International. 18th ed. Gaithersburg, MD: AOAC International; 2005.

21. Stein HH, Sève B, Fuller MF, Moughan PJ, de Lange CFM. Invited review: amino acid bio- 
availability and digestibility in pig feed ingredients: terminology and application. J Anim Sci. 2007;85:172-80. https://doi.org/10.2527/jas.2005-742

22. Kyoung H, Lee JJ, Cho JH, Choe J, Kang J, Lee H, et al. Dietary glutamic acid modulates immune responses and gut health of weaned pigs. Animals. 2021;11:504. https://doi.org/10.3390/ ani11020504

23. Zhang S, Yoo DH, Ao X, Kim IH. Effects of dietary probiotic, liquid feed and nutritional concentration on the growth performance, nutrient digestibility and fecal score of weaning piglets. Asian-Australas J Anim Sci. 2020;33:1617-23. https://doi.org/10.5713/ajas.19.0473

24. Wang Y, Cho JH, Chen YJ, Yoo JS, Huang Y, Kim HJ, et al. The effect of probiotic BioPlus $2 \mathrm{~B}^{\circledR}$ on growth performance, dry matter and nitrogen digestibility and slurry noxious gas emission in growing pigs. Livest Sci. 2009;120:35-42. https://doi.org/10.1016/j.livsci.2008.04.018

25. Jørgensen JN, Laguna JS, Millán C, Casabuena O, Gracia MI. Effects of a Bacillus-based probiotic and dietary energy content on the performance and nutrient digestibility of wean to finish pigs. Anim Feed Sci Technol. 2016;221:54-61. https://doi.org/10.1016/j.anifeedsci.2016.08.008

26. Luise D, Bertocchi M, Motta V, Salvarani C, Bosi P, Luppi A, et al. Bacillus sp. probiotic supplementation diminish the Escherichia coli F4ac infection in susceptible weaned pigs by influencing the intestinal immune response, intestinal microbiota and blood metabolomics. J Anim Sci Biotechnol. 2019;10:74. https://doi.org/10.1186/s40104-019-0380-3

27. Lan R, Tran H, Kim I. Effects of probiotic supplementation in different nutrient density diets on growth performance, nutrient digestibility, blood profiles, fecal microflora and noxious gas emission in weaning pig.J Sci Food Agric. 2017;97:1335-41. https://doi.org/10.1002/jsfa.7871

28. Wang H, Kim KP, Kim IH. Influence of Bacillus subtilis GCB-13-001 on growth performance, nutrient digestibility, blood characteristics, faecal microbiota and faecal score in weanling pigs.J Anim Physiol Anim Nutr. 2019;103:1919-25. https://doi.org/10.1111/jpn.13199

29. Hwang KY, Cho JH, Lee JY, Kang KD, Seong SI, Kim IH. The benefits of using Bacillus as a probiotic.J Anim Vet Adv. 2012;11:3457-62. https://doi.org/10.3923/javaa.2012.3457.3462

30. Piewngam P, Zheng Y, Nguyen TH, Dickey SW, Joo HS, Villaruz AE, et al. Pathogen elimination by probiotic Bacillus via signalling interference. Nature. 2018;562:532-7. https://doi. org/10.1038/s41586-018-0616-y

31. Priest FG. Extracellular enzyme synthesis in the genus Bacillus. Bacteriol Rev. 1977;41:711-53. https://doi.org/10.1128/br.41.3.711-753.1977

32. Das G, Prasad MP. Isolation, purification \& mass production of protease enzyme from Bacillus subtilis. Int Res J Microbiol. 2010;1:26-31.

33. Hampson DJ. Alterations in piglet small intestinal structure at weaning. Res Vet Sci. 1986;40:32-40. https://doi.org/10.1016/S0034-5288(18)30482-X

34. Yang H, Xiong X, Wang X, Li T, Yin Y. Effects of weaning on intestinal crypt epithelial cells in piglets. Sci Rep. 2016;6:36939. https://doi.org/10.1038/srep36939

35. Cai L, Indrakumar S, Kiarie E, Kim IH. Effects of a multi-strain Bacillus species-based direct-fed microbial on growth performance, nutrient digestibility, blood profile, and gut health in nursery pigs fed corn-soybean meal-based diets. J Anim Sci. 2015;93:4336-42. https://doi. org/10.2527/jas.2015-9056

36. Liu Y, Song M, Che TM, Almeida JAS, Lee JJ, Bravo D, et al. Dietary plant extracts alleviate diarrhea and alter immune responses of weaned pigs experimentally infected with a pathogenic Escherichia coli.J Anim Sci. 2013;91:5294-306. https://doi.org/10.2527/jas.2012-6194

37. Li Y, Zhang H, Su W, Ying Z, Chen Y, Zhang L, et al. Effects of dietary Bacillus amyloliquefaciens supplementation on growth performance, intestinal morphology, inflammatory re- 
sponse, and microbiota of intra-uterine growth retarded weanling piglets. J Anim Sci Biotechnol. 2018;9:22. https://doi.org/10.1186/s40104-018-0236-2

38. Walsh MC, Sholly DM, Hinson RB, Saddoris KL, Sutton AL, Radcliffe JS, et al. Effects of water and diet acidification with and without antibiotics on weanling pig growth and microbial shedding.J Anim Sci. 2007;85:1799-808. https://doi.org/10.2527/jas.2006-049

39. Bhandari SK, Xu B, Nyachoti CM, Giesting DW, Krause DO. Evaluation of alternatives to antibiotics using an Escherichia coli K88+ model of piglet diarrhea: effects on gut microbial ecology.J Anim Sci. 2008;86:836-47. https://doi.org/10.2527/jas.2006-822

40. Choi JY, Shinde PL, Ingale SL, Kim JS, Kim YW, Kim KH, et al. Evaluation of multi-microbe probiotics prepared by submerged liquid or solid substrate fermentation and antibiotics in weaning pigs. Livest Sci. 2011;138:144-51. https://doi.org/10.1016/j.livsci.2010.12.015

41. Deng B, Wu J, Li X, Zhang C, Men X, Xu Z. Effects of Bacillus subtilis on growth performance, serum parameters, digestive enzyme, intestinal morphology, and colonic microbiota in piglets. AMB Express. 2020;10:212. https://doi.org/10.1186/s13568-020-01150-z

42. Zhang W, Zhu YH, Zhou D, Wu Q, Song D, Dicksved J, et al. Oral administration of a select mixture of Bacillus probiotics affects the gut microbiota and goblet cell function following Escherichia coli challenge in newly weaned pigs of genotype MUC4 that are supposed to be enterotoxigenic E. coli F4ab/ac receptor negative. Appl Environ Microbiol. 2017;83:e0274716. https://doi.org/10.1128/AEM.02747-16

43. Klaenhammer TR, Kleerebezem M, Kopp MV, Rescigno M. The impact of probiotics and prebiotics on the immune system. Nat Rev Immunol. 2012;12:728-34. https://doi.org/10.1038/ nri3312

44. Zeuthen LH, Fink LN, Frokiaer H. Epithelial cells prime the immune response to an array of gut-derived commensals towards a tolerogenic phenotype through distinct actions of thymic stromal lymphopoietin and transforming growth factor- $\beta$. Immunology. 2008;123:197-208.

45. Zhou D, Zhu YH, Zhang W, Wang ML, Fan WY, Song D, et al. Oral administration of a select mixture of Bacillus probiotics generates Tr1 cells in weaned F4ab/acR- pigs challenged with an F4+ ETEC/VTEC/EPEC strain. Vet Res. 2015;46:95. https://doi.org/10.1186/ s13567-015-0223-y

46. Laskowska E, Jarosz $€$, Grądzki Z. Effect of multi-microbial probiotic formulation bokashi on pro- and anti-inflammatory cytokines profile in the serum, colostrum and milk of sows, and in a culture of polymorphonuclear cells isolated from colostrum. Probiotics Antimicrob Proteins. 2019;11:220-32. https://doi.org/10.1007/s12602-017-9380-9

47. McDermott MF. TNF and TNFR biology in health and disease. Cell Mol Biol. 2001;47:61935.

48. Zganiacz A, Santosuosso M, Wang J, Yang T, Chen L, Anzulovic M, et al. TNF- $\alpha$ is a critical negative regulator of type 1 immune activation during intracellular bacterial infection. J Clin Invest. 2004;113:401-13. https://doi.org/10.1172/JCI18991

49. Izadpanah K, Freyer D, Weber JR, Braun JS. Brain parenchymal TNF- $\alpha$ and IL-1 $\beta$ induction in experimental pneumococcal meningitis. J Neuroimmunol. 2014;276:104-11. https://doi. org/10.1016/j.jneuroim.2014.08.625

50. Lan RX, Lee SI, Kim IH. Effects of multistrain probiotics on growth performance, nutrient digestibility, blood profiles, faecal microbial shedding, faecal score and noxious gas emission in weaning pigs. J Anim Physiol Anim Nutr. 2016;100:1130-8. https://doi.org/10.1111/ jpn.12501

51. Mach N, Berri M, Estellé J, Levenez F, Lemonnier G, Denis C, et al. Early-life establishment of the swine gut microbiome and impact on host phenotypes. Environ Microbiol Rep. 
2015;7:554-69. https://doi.org/10.1111/1758-2229.12285

52. Gaukroger CH, Stewart CJ, Edwards SA, Walshaw J, Adams IP, Kyriazakis I. Changes in faecal microbiota profiles associated with performance and birthweight of piglets. Front Microbiol. 2020;11:917. https://doi.org/10.3389/fmicb.2020.00917

53. Fouhse JM, Zijlstra RT, Willing BP. The role of gut microbiota in the health and disease of pigs. Anim Front. 2016;6:30-6. https://doi.org/10.2527/af.2016-0031

54. Shang Q, Shan X, Cai C, Hao J, Li G, Yu G. Dietary fucoidan modulates the gut microbiota in mice by increasing the abundance of Lactobacillus and Ruminococcaceae. Food Funct. 2016;7:3224-32. https://doi.org/10.1039/C6FO00309E

55. Pieper R, Janczyk P, Zeyner A, Smidt H, Guiard V, Souffrant WB. Ecophysiology of the developing total bacterial and Lactobacillus communities in the terminal small intestine of weaning piglets. Microb Ecol. 2008;56:474-83. https://doi.org/10.1007/s00248-008-9366-y

56. Kovatcheva-Datchary P, Nilsson A, Akrami R, Lee YS, De Vadder F, Arora T, et al. Dietary fiber-induced improvement in glucose metabolism is associated with increased abundance of Prevotella. Cell Metab. 2015;22:971-82. https://doi.org/10.1016/j.cmet.2015.10.001

57. Ding H, Zhao X, Ma C, Gao Q, Yin Y, Kong X, et al. Dietary supplementation with Bacillus subtilis DSM 32315 alters the intestinal microbiota and metabolites in weaned piglets.J Appl Microbiol. 2020;130:217-32. https://doi.org/10.1111/jam.14767

58. Cui K, Iv X, Diao Q, Zhang N. Effects of dietary supplementation with Bacillus subtilis and yeast culture on growth performance, nutrient digestibility, serum indices and faeces microbiota of weaned piglets. J Anim Feed Sci. 2019;28:328-36. https://doi.org/10.22358/ jafs/114238/2019 